\title{
Optimization of Vehicle Suspension System to Improve Comfort
}

\author{
E. S. Fernandes, S. S. Sheth, K. K. Nawpute, V. V. Kadam, A. C. Mitra \\ (Department of Mechanical Engineering, M.E.S College of Engineering, S.P. Pune University, India)
}

\begin{abstract}
Design of suspension system has always been a tiresome task. This paper deals with finding the optimum values of suspension and steering parameters to give the best ride comfort as per ISO 2631-1:1997. An ADAMS model is prepared and validated, which has the capability of altering seven different influential parameters namely sprung mass, un-sprung mass, spring stiffness, damping coefficient, tire stiffness, camber and toe. In order to obtain optimal values for each parameter the Design of Experiment approach is implemented. MINITAB ${ }^{\circledR}$ is used to obtain a regression model which gives reliable values of $R$-sq $\left.93.67 \%\right)$ and $R$-sq (adj) (92.41\%). The ADAMS model was then tested with the optimized parameters thus attaining an accuracy of $67.86 \%$.
\end{abstract}

Keywords - ADAMS, Camber angle, Damping Coefficient, DOE, Sprung mass, Ride comfort, RMS, Spring stiffness, Toe.

\section{INTRODUCTION}

The mechanism that was designed and is implemented in vehicles to ensure a passenger a comfortable ride simultaneously keeping the wheels in contact with the road for any road condition is called a suspension system. As per ISO 2631-1:1997 standards, humans are more sensitive to vertical vibrations ranging from 4 to 8 Hz. In this paper as per ISO 2631-1:1997, ride comfort has been assessed in RMS acceleration of sprung mass [1]. An experiment was conducted using different cars running at different speeds on various road profiles to examine the effects of vibrations on the passengers. Many conclusions were drawn regarding the effects of vibrations related to the acceleration levels of the vehicle with respect to the road, amount of time the passengers were exposed to a particular road profile [2].The various effects of vibration can be reduced by studying in detail the parameters of the suspension system used. In a research by Yunqing Zhang et al. fractional damping had been implemented in Matlab/Simulink for investigating vehicle non-stationary vibration process. Also the response of the body was analyzed at $30 \mathrm{~m} / \mathrm{s}$ with two acceleration which concluded that vibrations were more for higher accelerations. Frequency response was also analyzed using FFT (Fast Fourier Transform) Algorithm [3]. In a research by Saeed Mostaani et al. a model with 7-DOF had been created and analyzed to evaluate and optimize ride comfort and pitch angle. Hence spring and damper values for front and rear sections had been varied. In the end a DOE method had been implemented to obtain maximum ride comfort from the best values of the varied parameters [4]. In a thesis by Alexander Varghese. In Matlab/Simulink, three mathematical models were developed to analyze and evaluate the effects of tire pressure on consumption of fuel, handling of the vehicle and ride characteristics. Also evaluation in time and frequency domain was done for a 4DOF half car model that had been developed and subjected to sine input, step input and random road profile input. It had been concluded that at low tire pressure vertical accelerations were less while at high tire pressures displacement of sprung mass is negligibly less compared to low pressures [5]. In a paper by Abdelrahman Abdelghaffar et al., vibrational transmissibility in cars was analyzed due the effects of tire pressure. Also at certain frequencies, amplitudes of vibration were studied by varying tire pressure from 20 to 40 psi with the help of the FFT. It was concluded that the vibrational transmissibility was found to reduce when tire pressure was reduced, but reducing tire pressure after a threshold compromised driver's safety i.e. handling [6].

S. Prabhakar, Dr.K.Arunachalam used variable damping and stiffness parameters for carrying out the simulation of a quarter car suspension system. While implementing step and random road profile as input, ride comfort was maximized along with better road holding [7]. M. Zehsaz1 et al. have carried out the influence of the different parameters on dynamic control and ride comfort during acceleration and braking of an off road vehicle. The dynamic behavior of the vehicle as well as the road profile was developed in Matlab. Results obtained showed that decreasing spring coefficient decreases sprung mass resonance frequency. It was also concluded that ride comfort is more sensitive to rear damper [8]. Javad Marzbanrad, Masoud Mohammadi and Saeed Mostaani determined values for spring and damper in order to obtain optimum ride comfort at different speeds using Design of Experiment method (DOE) [9]. As important as analyzing various parameters individually, it is essential to combine these parameters together to find an optimum value of ride comfort for broad range of input parameter values. Based on this, A.C Mitra et al. found an optimum value of road holding as well as ride comfort for various combinations of suspension input parameters such as spring stiffness, 
damping coefficient, toe and camber, un-sprung and sprung mass, tire pressure and wheel speed using Design of Experiments. An average accuracy of $80 \%$ was obtained by using the obtained optimal values on the test rig [10]. A.C Mitra et al. used $2^{\mathrm{k}}$ full factorial method to obtain optimum values of ride comfort and road holding considering damping coefficient, spring stiffness, speed and sprung mass. Test rig values were compared to the values obtained by a model prepared in SIMULINK and a correlation of 0.64 was obtained [11]. In another research A.C Mitra et al. optimized ride comfort maintaining a good value for road holding using Genetic Algorithm (GA). The objective functions of $\mathrm{RH}$ and $\mathrm{RC}$ were derived in terms of damping coefficient and spring stiffness [12]. A.C Mitra et al. modeled a 4-DOF system by using SIMULINK for analyzing ride comfort. Optimization was carried by Genetic Algorithm, using parameters such as damper coefficient, spring stiffness, sprung and un-sprung mass, tire stiffness. Results of original and optimized suspension system were compared for sprung mass acceleration, road holding as well as driver head acceleration [13].Jin Liu, Yongjun Shen, Shaopu Yang carried out two methods based on invariant point method for optimizing the spring-damper mechanism of the passive suspension system. It was concluded that the ride comfort for the two passive suspension systems had increased, also the suspension deformation was more than the original suspension system but within range and lastly, the tire deformation was the same for the optimized and original suspension system [14]. Arshad Mehmood, Ahmad Ali Khan, Ayaz Mehmood implemented parameters such as un-sprung mass, sprung mass, damping coefficient, spring stiffness and tire stiffness. Damping coefficient was considered as a parameter for optimization. Also using root locus plots stability analysis was carried out for the optimized values [15]. A. Elsawaf and T. Vampola considered front suspension stiffness, rear suspension stiffness, front dynamic coefficient and rear dynamic coefficient as parameters to be optimized. Optimization was done by Particle Swamp Optimization Technique (PSO). After simulation and assessment of the vehicle considering various speed control profiles, it was concluded that the optimized passive suspension system had better performance [16].

Zhongzhe Chi, Yuping He and Greg F. Naterer optimized a suspension system for a quarter car model concerning vertical body acceleration, suspension working space and dynamic tire load using Genetic Algorithms (GAs), Sequential Quadratic Program and Pattern Search Algorithm (PSA). The three algorithms were then compared, it was concluded that the SQP had a very strong local convergence and theoretical properties and GA and PSA are more useful to find global optimal points [17]. Anil Shirahatti et al. used Genetic algorithm to design a suspension system in order to minimize maximum seat and sprung mass bouncing acceleration, root mean square (RMS) acceleration of sprung mass and seat confining to the ISO2631 standards as well as minimizing suspension travel, tire deflection, road holding and jerk. Based on the results, it was concluded that the optimized suspension system had an improved ride comfort and road holding [18]. R Alkhatib, G Nakhaie Jazar, M.F Golnaraghi implemented genetic algorithm to optimize a 1 DOF vibration isolator. This method was then used for optimizing a linear suspension system. Results showed an optimal relation to exist between RMS of relative displacement and RMS of absolute acceleration [19].Shijil Pet al. design and analyzed a suspension system by studying the static and dynamic parameters of the suspension system. The different parameters identified were optimized to obtain a better performance [20]. M. Mahmoodi-Kaleibar et al. used MSC ADAMS to carry out optimization of the suspension system implementing Genetic Algorithm which improved ride comfort as well as handling. Simulation results showed that the optimized system had lower camber angle variations [21].P.Senthil Kumar et al. optimized a passenger vehicle suspension system considering stiffness and damping coefficient of shock absorber, stiffness and damping coefficient of the seat as input parameters. The design of experiments was planned by using L27 orthogonal array with 4 factors at 3 levels. On analysis of $\mathrm{S} / \mathrm{N}$ ratio, optimum values for settling time and seat displacement were obtained [22]. A.C Mitra et al. reduced variability in the Ride comfort using Taguchi method for optimization adapted along with ANOVA and design of experiments methodology. The main aim was to find various combinations of input parameters used [23]. Adrian Florea et al. implemented various multi objective evolutionary algorithms along with different road profiles to obtain the best solution for an optimized suspension system. The optimum design variable were spring and damping coefficients in order to minimize sprung mass displacement and sprung mass acceleration constraint to suspension working space, natural frequency and maximum vehicle vertical acceleration [24]. One of the basic reasons for vibration is road input. A research by Galal Ali Hassaan investigated the step response of a 2 DOF passive suspension system. The mathematical models for sprung mass acceleration and displacement of the quarter car model were used for analysis [25]. Galal Ali Hassaan showed that using a novel polynomial hump ride comfort conditions can be reached assuming linear characteristics for the passive suspension system at speeds 5 and $30 \mathrm{~km} / \mathrm{hr}$ [26].

In this paper an ADAMS model is prepared which is used for analysis and data acquisition. The model has the ability to vary its sprung mass, un-sprung mass, spring stiffness, damping coefficient, tire stiffness, camber and toe for which a sin bump is used as road input and analysis is carried out at a constant speed of 20 $\mathrm{kmph}$. DOE is used to check the predictability of the model and also to find a regression model which can be 
used to optimize suspension systems. Furthermore sensitivity analysis is carried out to examine the effect of individual parameters on ride comfort.

\section{DEVELOPMENT OF MSC OF ADAMS SIMULATION MODEL}

A front wheel suspension system was prepared in MSC ADAMS. The dimensions of the test-rig were measured and then an ADAMS model was developed with the measured dimensions. The model has capability to vary seven different parameters namely Sprung Mass (Ms), Un-sprung Mass (Mu), Spring Stiffness (Ks), Damping Coefficient (Cs), Tire Stiffness (Kt) and also the steering geometry parameters such as Camber (Cam) and Toe. Various simulations were carried out according to the DOE table prepared in MINITAB ${ }^{\circledR}$ using the full factorial design method. Fig.1 shows the front wheel suspension system model. Both the tires are given the same jack motion thus behaving and following the characteristics of a quarter-car model.

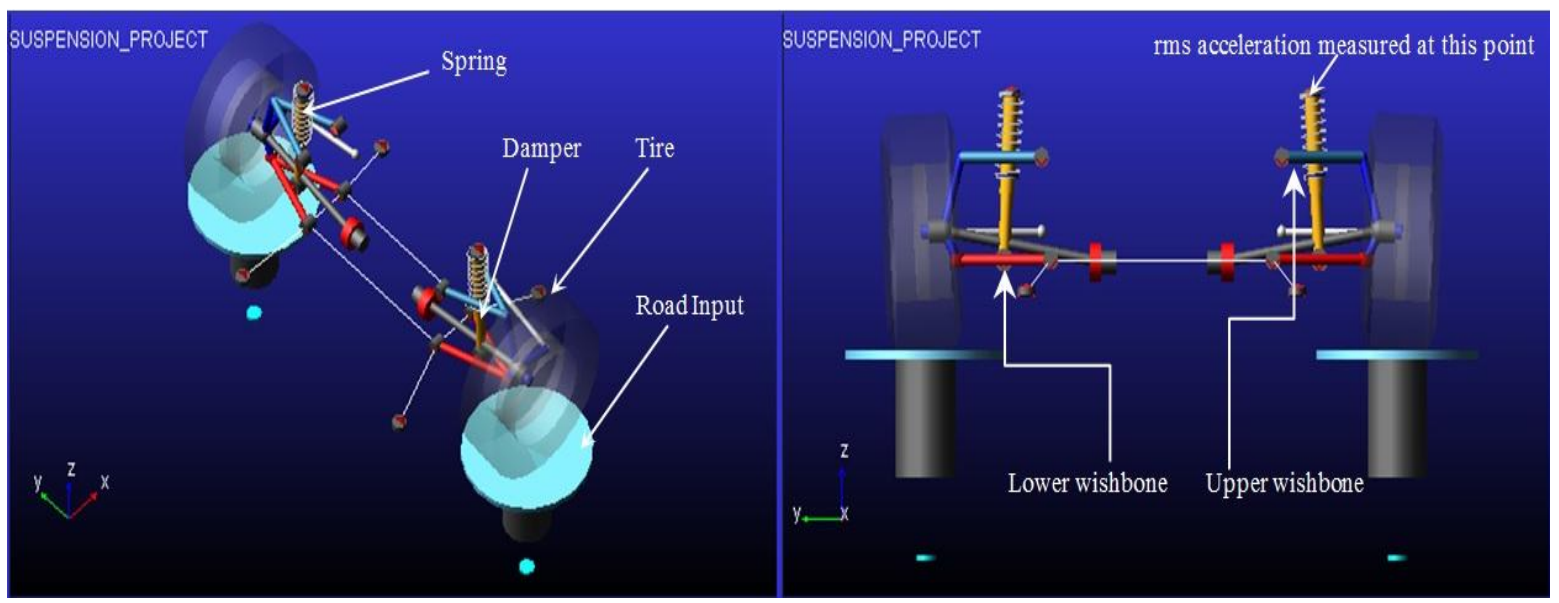

Fig.1: Developed Simulation Model in MSC ADAMS

\section{DESIGN OF EXPERIMENTS}

The main goal of the work is to obtain optimized values of the influential parameters and their interaction to attain the best possible ride comfort. Design of Experiments (DOE) is an instrument to determine the relationship between factors affecting a process and the output of that process. In other words, it is used to find cause-and-effect relationships. This information is needed to manage process inputs in order to optimize the output. In this paper full factorial method has been employed to carry out the DOE.

\subsection{Full Factorial}

Full Factorial method of DOE is used since more than two factors are considered in this research and each factors have different 'high' and 'low' or 'levels'. Full Factorial method tackles all these levels through all the factors. It also helps in understanding the effect of each factor on response variable RC and furthermore provides the effects of interactions between factors on the response variable RC. Even though full factorial method increases the number of reading it gives more accurate results.

Table 1. Upper and Lower Limits of Input Parameters

\begin{tabular}{|l|l|l|l|}
\hline INPUT PARAMETERS & UPPER LIMIT $(+1)$ & LOWER LIMIT (-1) & \\
\hline Sprung Mass - Ms (Kg) & 1250 & 500 & \\
\hline Un-Sprung Mass - Mu (Kg) & 60 & 25 & \\
\hline Spring Stiffness - Ks (N/m) & 10000 & 20000 & \\
\hline Damping Coefficient - Cs (N-s/m) & 400 & 1500 & \\
\hline Tire Stiffness - Kt (N/m) & 100000 & 150000 & \\
\hline Camber - Cam (Deg) & 2 & 0 & \\
\hline Toe - Toe (Deg) & 1 & 0 & \\
\hline
\end{tabular}

\subsection{Data Assimilation}

Values of seven factors with two levels each (Upper Limit and Lower Limit) as shown in table 1, were acquired by research and market survey. The design is denoted as $2^{\mathrm{k}}$ where $k$ is the number of factors, therefore it is denoted as $2^{7}$ giving us 128 runs and readings as shown in table 2 . These tests were carried out on the simulation model with a constant speed of $20 \mathrm{kmph}$ and a sine bump was used as a road input to the tires. 
Table 2. Observation Table

\begin{tabular}{|c|c|c|c|c|c|c|c|c|c|c|c|c|c|c|c|c|c|}
\hline $\begin{array}{l}\text { Run } \\
\text { Order }\end{array}$ & Ms & Mu & Ks & $\mathrm{Cs}_{\mathrm{s}}$ & Kt & Cam & Toe & $\overline{R C}$ & $\begin{array}{c}\text { Run } \\
\text { Order }\end{array}$ & Ms & Mu & Ks & $\mathrm{Cs}_{5}$ & Kt & Cam & \begin{tabular}{|l|} 
Toe \\
\end{tabular} & $\mathrm{RC}$ \\
\hline 1 & 500 & 25 & 20000 & 400 & 150000 & 2 & 0 & 0.3779 & 47 & 1250 & 60 & 10000 & 400 & 150000 & 0 & 1 & 0.2294 \\
\hline 2 & 500 & 60 & 10000 & 1500 & 150000 & 2 & 1 & 0.7083 & 48 & 500 & 25 & 10000 & 1500 & 150000 & 0 & 0 & 0.6138 \\
\hline 3 & 500 & 25 & 20000 & 400 & 150000 & 0 & 1 & 0.3831 & 49 & 500 & 60 & 10000 & 400 & 150000 & 2 & 0 & 0.2094 \\
\hline 4 & 1250 & 25 & 20000 & 400 & 100000 & 0 & 1 & 0.1894 & 50 & 1250 & 25 & 20000 & 400 & 150000 & 2 & 0 & 0.3779 \\
\hline 5 & 1250 & 60 & 20000 & 400 & 100000 & 0 & 1 & 0.167 & 51 & 1250 & 25 & 10000 & 400 & 100000 & 2 & 0 & 0.1686 \\
\hline 6 & 500 & 60 & 20000 & 400 & 150000 & 2 & 0 & 0.2224 & 52 & 1250 & 60 & 10000 & 1500 & 150000 & 2 & 0 & 0.7386 \\
\hline 7 & 1250 & 25 & 20000 & 1500 & 150000 & 2 & 0 & 1.2454 & 53 & 500 & 60 & 10000 & 1500 & 100000 & 2 & 1 & 0.5737 \\
\hline 8 & 500 & 60 & 20000 & 1500 & 150000 & 2 & 0 & 0.7283 & 54 & 1250 & 25 & 10000 & 1500 & 100000 & 0 & 0 & 0.4653 \\
\hline 9 & 1250 & 25 & 10000 & 1500 & 150000 & 0 & 0 & 0.6026 & 55 & 1250 & 60 & 10000 & 400 & 150000 & 2 & 0 & 0.2269 \\
\hline 10 & 1250 & 25 & 20000 & 400 & 150000 & 0 & 0 & 0.341 & 56 & 500 & 25 & 20000 & 1500 & 150000 & 0 & 1 & 0.765 \\
\hline 11 & 1250 & 25 & 10000 & 1500 & 100000 & 2 & 0 & 0.4536 & 57 & 1250 & 25 & 20000 & 1500 & 100000 & 0 & 0 & 0.4832 \\
\hline 12 & 1250 & 60 & 10000 & 400 & 100000 & 2 & 0 & 0.1595 & 58 & 1250 & 60 & 10000 & 1500 & 150000 & 0 & 1 & 0.7307 \\
\hline 13 & 500 & 60 & 20000 & 1500 & 100000 & 2 & 0 & 0.5404 & 59 & 500 & 25 & 20000 & 400 & 100000 & 2 & 0 & 0.1821 \\
\hline 14 & 500 & 25 & 20000 & 1500 & 100000 & 0 & 0 & 0.4758 & 60 & 500 & 60 & 10000 & 400 & 150000 & 0 & 1 & 0.2321 \\
\hline 15 & 500 & 25 & 20000 & 400 & 150000 & 2 & 1 & 0.3633 & 61 & 500 & 60 & 10000 & 1500 & 100000 & 2 & 0 & 0.5737 \\
\hline 16 & 1250 & 25 & 20000 & 400 & 100000 & 0 & 0 & 0.1892 & 62 & 1250 & 60 & 10000 & 400 & 100000 & 0 & 0 & 0.1709 \\
\hline 17 & 1250 & 60 & 10000 & 400 & 150000 & 0 & 0 & 0.2294 & 63 & 500 & 60 & 20000 & 1500 & 150000 & 0 & 0 & 0.7431 \\
\hline 18 & 500 & 25 & 10000 & 400 & 100000 & 2 & 0 & 0.1584 & 64 & 500 & 60 & 20000 & 400 & 150000 & 0 & 0 & 0.654 \\
\hline 19 & 500 & 25 & 10000 & 400 & 150000 & 0 & 1 & 0.2177 & 65 & 500 & 25 & 20000 & 1500 & 100000 & 2 & 1 & 0.484 \\
\hline 20 & 500 & 60 & 10000 & 1500 & 150000 & 2 & 0 & $\begin{array}{l}0.7124 \\
13124\end{array}$ & 66 & 1250 & 25 & 20000 & 400 & 150000 & 0 & 1 & 0.4009 \\
\hline $\begin{array}{l}21 \\
22\end{array}$ & 500 & 25 & $\frac{20000}{20000}$ & 1500 & $\begin{array}{l}150000 \\
100000\end{array}$ & $\frac{2}{0}$ & $\frac{0}{0}$ & \begin{tabular}{l|}
1.3114 \\
0.1726
\end{tabular} & 67 & 1250 & 25 & 10000 & 1500 & 150000 & 0 & 1 & 1.2761 \\
\hline $\begin{array}{l}22 \\
23\end{array}$ & 500 & 60 & 10000 & 400 & 100000 & $\frac{0}{0}$ & $\frac{0}{1}$ & $\begin{array}{l}0.1726 \\
0.1709\end{array}$ & 68 & 1250 & 60 & 10000 & 1500 & 150000 & 0 & 0 & 0.7263 \\
\hline 24 & 500 & 25 & 10000 & 400 & 150000 & 2 & 0 & 0.2139 & 69 & 500 & 60 & 10000 & 400 & 100000 & 2 & 0 & 0.1695 \\
\hline 25 & 1250 & 25 & 10000 & 1500 & 150000 & 2 & 1 & 1.2961 & 70 & 1250 & 60 & 20000 & 400 & 100000 & 2 & 1 & 0.1538 \\
\hline 26 & 500 & 60 & 20000 & 400 & 100000 & 2 & 1 & 0.169 & 71 & 1250 & 25 & 10000 & 400 & 150000 & 2 & 0 & 0.2294 \\
\hline 27 & 500 & 25 & 10000 & 1500 & & 0 & 0 & 0.169 & 72 & 500 & 60 & 10000 & 400 & 150000 & 0 & 0 & 0.2155 \\
\hline 28 & 1250 & 60 & 10000 & 1000 & 10000 & 0 & 1 & 0.4581 & 73 & 1250 & 25 & 20000 & 1500 & 100000 & 2 & 1 & 0.4775 \\
\hline 29 & 500 & 25 & 20000 & 400 & 100000 & 0 & 1 & 0.1717 & 74 & 500 & 25 & 20000 & 400 & 100000 & 2 & 1 & 0.1846 \\
\hline 30 & 500 & 25 & 20000 & 400 & 100000 & 0 & 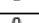 & 0.1894 & 75 & 500 & 25 & 10000 & 400 & 100000 & 2 & 1 & 0.178 \\
\hline 31 & & & & & 150000 & 0 & & 0.3831 & 76 & 1250 & 60 & 20000 & 1500 & 150000 & 2 & 1 & 0.7947 \\
\hline & & & & & 100000 & 0 & 1 & 0.5828 & 77 & 1250 & 60 & 20000 & 400 & 100000 & 0 & 0 & 0.1787 \\
\hline 33 & & & & & 150000 & 0 & 1 & 0.2405 & 78 & 500 & 25 & 10000 & 400 & 150000 & 0 & 0 & 0.2467 \\
\hline 34 & & & 10000 & 1500 & 100000 & 0 & 1 & 0.577 & 79 & 500 & 60 & 10000 & 400 & 100000 & 0 & 0 & 0.1842 \\
\hline 35 & & 25 & 20000 & 1500 & 150000 & 0 & 1 & 1.3277 & 80 & 1250 & 60 & 10000 & 1500 & 100000 & 0 & 0 & 0.6051 \\
\hline 36 & & 25 & 20000 & 1500 & 150000 & 0 & 0 & 1.3277 & 81 & 1250 & 25 & 20000 & 1500 & 100000 & 2 & 0 & 0.5018 \\
\hline 37 & & 25 & 10000 & 1500 & 100000 & 2 & 1 & 0.4722 & 82 & 1250 & 25 & 10000 & 400 & 100000 & 2 & 1 & 0.1784 \\
\hline 38 & & 60 & 20000 & 400 & 150000 & 0 & 0 & 0.2364 & 83 & 1250 & 60 & 20000 & 400 & 150000 & 0 & 1 & 0.2367 \\
\hline 40 & & 25 & 20000 & 1500 & 100000 & 2 & 0 & 0.4834 & 85 & 1250 & 25 & 20000 & 400 & 150000 & 2 & 1 & 0.4656 \\
\hline 41 & & & & & 150000 & 2 & 1 & 0.2256 & 86 & 500 & 60 & 20000 & 1500 & 150000 & 2 & 1 & 0.7544 \\
\hline 42 & & & 10000 & 400 & 100000 & 2 & 1 & 0.1733 & 87 & 1250 & 60 & 10000 & 1500 & 100000 & 2 & 1 & 0.634 \\
\hline 43 & 500 & 25 & 20000 & 400 & 100000 & 0 & 0 & 0.1897 & 88 & 500 & 60 & 20000 & 1500 & 100000 & 0 & 0 & 0.6415 \\
\hline & 500 & 25 & 10000 & 400 & 100000 & 0 & 0 & 0.1758 & 90 & 1250 & 60 & 20000 & 1500 & 100000 & 2 & 1 & 0.6661 \\
\hline & & 25 & 10000 & 400 & 100000 & 0 & 0 & 0.1758 & 91 & 1250 & 60 & 10000 & 1500 & 100000 & 2 & 0 & 0.5764 \\
\hline & 500 & 60 & 20000 & 400 & 100000 & 2 & 0 & 0.1697 & 92 & 1250 & 25 & 10000 & 400 & 100000 & 0 & 1 & 0.1747 \\
\hline $\begin{array}{l}\text { Kon } \\
\text { Order }\end{array}$ & Wots & Thu & $\mathrm{ks}$ & cs & $\mathrm{kt}$ & Cam & Toe & RC & $\begin{array}{l}\text { Run } \\
\text { Order }\end{array}$ & Ms & $\mathrm{Mu}$ & Ks & $\mathrm{Cs}_{5}$ & Kt & Cam & Toe & $\mathbf{R C}$ \\
\hline 93 & 1250 & 25 & 20000 & 400 & 100000 & 2 & 1 & 0.186 & 111 & 1250 & 25 & 10000 & 1500 & 150000 & 2 & 0 & 1.3666 \\
\hline 94 & 500 & 60 & 20000 & 1500 & 150000 & 0 & 1 & 0.7345 & 112 & 1250 & 25 & 10000 & 1500 & 100000 & 0 & 1 & 0.487 \\
\hline 95 & 500 & 25 & 10000 & 400 & 100000 & 0 & 1 & 0.1775 & 113 & 1250 & 60 & 20000 & 1500 & 100000 & 2 & 0 & 0.5537 \\
\hline 96 & 1250 & 60 & 20000 & 1500 & 100000 & 0 & 1 & 0.6093 & 114 & 1250 & 60 & 10000 & 1500 & 150000 & 2 & 1 & 0.7337 \\
\hline 97 & 1250 & 60 & 20000 & 400 & 150000 & 2 & 1 & 0.2339 & 115 & 500 & 25 & 10000 & 1500 & 100000 & 0 & 1 & 0.4895 \\
\hline 98 & 1250 & 25 & 20000 & 1500 & 100000 & 0 & 1 & 0.47 & 116 & 500 & 25 & 10000 & 1500 & 100000 & 2 & 1 & 0.4765 \\
\hline 99 & 500 & 60 & 10000 & 1500 & 100000 & 0 & 1 & 0.657 & 117 & 500 & 60 & 10000 & 400 & 150000 & 2 & 1 & 0.2151 \\
\hline 100 & 500 & 60 & 10000 & 1500 & 150000 & 0 & 0 & 0.7487 & 118 & 1250 & 60 & 10000 & 400 & 100000 & 2 & 1 & 0.1894 \\
\hline 101 & 500 & 25 & 10000 & 1500 & 150000 & 2 & 1 & 1.3666 & 119 & 1250 & 60 & 20000 & 1500 & 150000 & 0 & 0 & 0.7345 \\
\hline 102 & 1250 & 60 & 20000 & 1500 & 150000 & 2 & 0 & 0.6966 & 120 & 500 & 25 & 20000 & 1500 & 100000 & 0 & 1 & 0.4902 \\
\hline 103 & 1250 & 25 & 20000 & 1500 & 150000 & 0 & 0 & 1.3023 & 121 & 500 & 25 & 20000 & 1500 & 150000 & 2 & 1 & 1.4089 \\
\hline 104 & 500 & 60 & 10000 & 1500 & 100000 & 0 & 0 & 0.555 & 122 & 1250 & 25 & 20000 & 1500 & 150000 & 2 & 1 & 1.4089 \\
\hline 105 & 500 & 60 & 20000 & 400 & 100000 & 0 & 1 & 0.1787 & 123 & 1250 & 25 & 10000 & 400 & 150000 & 2 & 1 & 0.2319 \\
\hline 106 & 500 & 60 & 20000 & 1500 & 100000 & 2 & 1 & 0.5512 & 124 & 1250 & 60 & 20000 & 1500 & 150000 & 0 & 1 & 0.7563 \\
\hline 107 & 500 & 25 & 10000 & 1500 & 150000 & 0 & 1 & 1.3833 & 125 & 1250 & 25 & 10000 & 400 & 150000 & 0 & 0 & 0.2467 \\
\hline 108 & 500 & 60 & 10000 & 1500 & 150000 & 0 & 1 & 0.7487 & 126 & 1250 & 25 & 20000 & 400 & 100000 & 2 & 0 & 0.1863 \\
\hline 109 & 1250 & 60 & 20000 & 400 & 150000 & 2 & 0 & 0.2439 & 127 & 500 & 25 & 10000 & 1500 & 100000 & 2 & 0 & 0.4802 \\
\hline 110 & 500 & 25 & 10000 & 400 & 150000 & 2 & 1 & 0.2338 & 128 & 1250 & 60 & 20000 & 1500 & 100000 & 0 & 0 & 0.5874 \\
\hline
\end{tabular}

\subsection{Goodness of Fit}

Table 3 gives us a quantitative effect of each parameter on $\mathrm{RC}$ and this is analyzed by deducing the value of ' $\mathrm{P}$ '. Table 3 also gives us a measureable 'effect' of each parameter and interactions (combinations of two or more factors) on the response which in turn is calculated by considering the average effects of the remaining parameters. The 'coefficient' term in table is the slope of the regression line and gives the predicted change in mean response with per unit increase in the factor keeping all other factors constant. The exactness of effect and coefficient is evaluated by standard error of coefficient or 'SE-coefficient'. 'T-value' is the ratio of coefficient and SE-coefficient according to which the 'P-value' is decided. If the 'P-value' is less than 0.05 i.e. a confidence level of $95 \%$ for the model, it is regarded as 'sensitive' and the null hypothesis is rejected as per TYPE-I error. $\mathrm{Kt}^{*} \mathrm{Cam} * \mathrm{Toe}, \mathrm{Mu} * \mathrm{Ks} * \mathrm{Cs}, \mathrm{Ms} * \mathrm{Ks}, \mathrm{Ms} * \mathrm{Kt}$ are few interactions which have value of ' $\mathrm{P}$ ' greater 6th National Conference RDME 2017, 17th-18th March 2017. 
than 0.05 hence are marked as insensitive. These analysis are carried out repetitively by eliminating the insensitive interactions until only the significant factors and interactions are attained. Insensitive parameters such as Cam, Toe, Ks*Cam, Ks*Toe, $\mathrm{Kt}^{*} \mathrm{Cam}$ and $\mathrm{Cam} * \mathrm{Toe}$, are essential to obtain the regression model. After removal of insignificant factors, the 'Goodness of Fit' is calculated signifying how close the predicted values are to the observed data values. ' $\mathrm{S}$ ' from Table 4 stands for standard error which is an approximation of errors or noise in the model. Smaller the value of S, greater is the accuracy of the analysis. Coefficient of determination or 'R-sq' indicates the model is justified by input parameters. Value of R-sq obtained in this research was 93.67\%. It is better to have high values of R-sq as it gives a better fit and gives a low value of variance, but having too many insignificant parameters can also result in a high R-sq value. To overcome this, R-sq (adj) is evaluated whose value should be close to the R-sq value to prove its legitimacy and its fitment to the model, 92.41\% obtained in this research. PRESS and R-sq (pred) values evaluates the predictability. R-sq (pred) shows the predictability of the model and minor difference between R-sq (pred) and R-sq signifies that the model is not over fit. Values obtained as per this experiment is given in table 4.

Table 3. Estimated Effects and Coefficients for RC

\begin{tabular}{|c|c|c|c|c|c|}
\hline Terms & Effect & Coefficient & SE Coefficient & $\mathbf{T}$ & $\mathbf{P}$ \\
\hline Constant & & 0.49118 & 0.008450 & 58.13 & 0.000 \\
\hline $\mathrm{Mu}$ & -0.10282 & -0.05141 & 0.008450 & -6.08 & 0.000 \\
\hline Ks & 0.04657 & 0.02329 & 0.008450 & 2.76 & 0.007 \\
\hline Cs & 0.52323 & 0.26162 & 0.008450 & 30.96 & 0.000 \\
\hline $\mathrm{Kt}$ & 0.27086 & 0.13543 & 0.008450 & 16.03 & 0.000 \\
\hline Cam & 0.02208 & 0.01104 & 0.008450 & 1.31 & 0.194 \\
\hline Toe & 0.02157 & 0.01079 & 0.008450 & 1.28 & 0.205 \\
\hline $\mathrm{Mu} * \mathrm{Cs}$ & -0.07314 & -0.03657 & 0.008450 & -4.33 & 0.000 \\
\hline $\mathrm{Mu} * \mathrm{Kt}$ & -0.15606 & -0.07803 & 0.008450 & -9.23 & 0.000 \\
\hline $\mathrm{Mu} * \mathrm{Cam}$ & -0.04295 & -0.02147 & 0.008450 & -2.54 & 0.012 \\
\hline $\mathrm{Ks} * \mathrm{Kt}$ & 0.04201 & 0.02100 & 0.008450 & 2.49 & 0.014 \\
\hline $\mathrm{Ks} * \mathrm{Cam}$ & -0.01575 & -0.00787 & 0.008450 & -0.93 & 0.353 \\
\hline Ks*Toe & -0.03227 & -0.01613 & 0.008450 & -1.91 & 0.059 \\
\hline $\mathrm{Cs} * \mathrm{Kt}$ & 0.16394 & 0.08197 & 0.008450 & 9.70 & 0.000 \\
\hline Cs*Cam & 0.03629 & 0.01815 & 0.008450 & 2.15 & 0.034 \\
\hline $\mathrm{Kt} * \mathrm{Cam}$ & 0.02873 & 0.01436 & 0.008450 & 1.70 & 0.092 \\
\hline Kt*Toe & 0.01246 & 0.00623 & 0.008450 & 0.74 & 0.462 \\
\hline Cam*Toe & 0.00255 & 0.00128 & 0.008450 & 0.15 & 0.880 \\
\hline $\mathrm{Mu} * \mathrm{Cs} * \mathrm{Kt}$ & -0.13465 & -0.06733 & 0.008450 & -7.97 & 0.000 \\
\hline $\mathrm{Mu} * \mathrm{Kt} * \mathrm{Cam}$ & -0.03811 & -0.01906 & 0.008450 & -2.26 & 0.026 \\
\hline Ks*Cam*Toe & 0.04418 & 0.02209 & 0.008450 & 2.61 & 0.010 \\
\hline $\mathrm{Cs} * \mathrm{Kt}^{*} \mathrm{Cam}$ & 0.03813 & 0.01907 & 0.008450 & 2.26 & 0.026 \\
\hline
\end{tabular}

Fig. 2 shows the Pareto chart which determines the magnitude and significance of a parameter or interaction visually. It comprises of a red line or a reference line corresponding to the critical $t$-value exceeding which any effect is significant. According to the chart parameters like toe, camber, sprung mass and interactions like $\mathrm{Ks}^{*}{ }^{*} \mathrm{Toe}, \mathrm{Kt}^{*} \mathrm{Cam}, \mathrm{Ks}{ }^{*} \mathrm{Cam}, \mathrm{Cam} *$ Toe are insignificant to evaluate RC.To assess the 'Goodness of Fit' qualitatively residual plots are examined. Fig. 3 shows such a residual 4-in-1 plot. In 'Normal Probability Plot' the plot follows a straight line if the errors are distributed normally. If the plotted points are at a substantial distance from the straight line it indicates inaccuracy in the model. Few large residual points are present which are considered as outliners. Histogram shows the residual points from all observations and forms a bell shaped graph. In residual vs fitted plot if the plot is dispersed along a constant horizontal line the model is known as homoscedastic i.e. all the parameters have the same finite variance and any curve or pattern shows that there are chances of heteroscedasticity. In this model since the plot shows a random distribution it states that the variance is constant throughout. The residual vs order plot shows the residual points in the order which they were carried out, it helps in determining the relationship between in the residuals. Since the graph shows no clear trend it signifies random variation in the experimental data.

Table 4. Regression Statics for RC

\begin{tabular}{|l|l|l|}
\hline S & Standard Deviation & 0.0955977 \\
\hline PRESS & Prediction Sum of Squares & 1.41257 \\
\hline R-Sq & Coefficient of Multiple Determination & $93.67 \%$ \\
\hline R-Sq (pred) & Predicted Coefficient of Determination & $90.76 \%$ \\
\hline R-Sq (adj) & Adjusted Coefficient of Determination & $92.41 \%$ \\
\hline
\end{tabular}

6th National Conference RDME 2017, 17th-18th March 2017. 


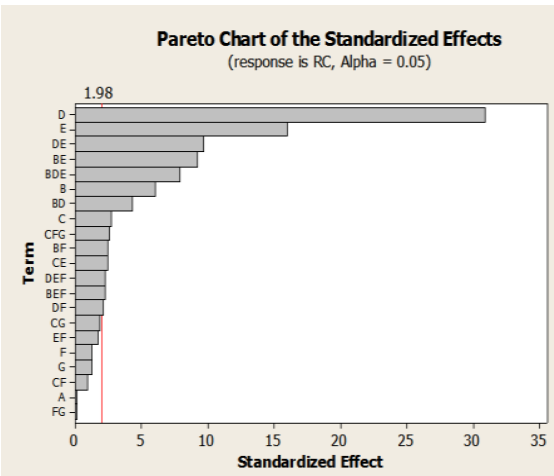

Fig.2: Pareto Chart of parameters in RC

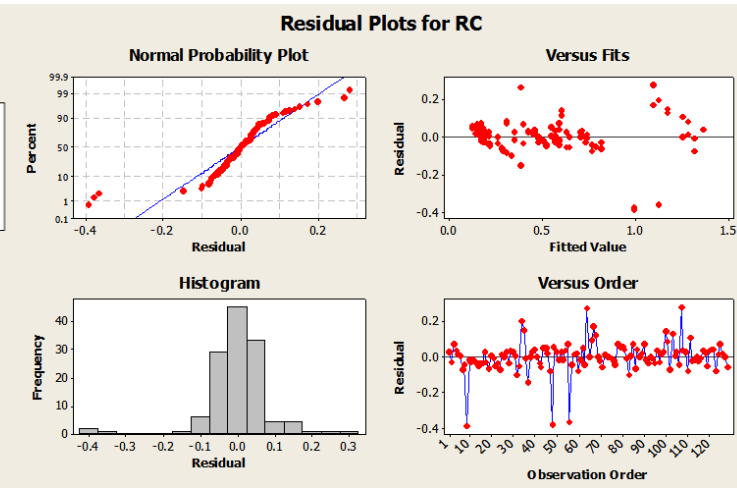

Fig.3: 4-in-1 Residuals Plots for RC

\subsection{Analysis of Variance (ANOVA)}

Table 5 shows the ANOVA (Analysis of Variance), the degree of freedom (DF) expresses the extent of information in each source and the source column consists of all the important parameters which may have a significant impact on variance in the model. Sequential sum of squares (Seq SS) and adjusted sum of squares (Adj SS) shows the variance considering that the previous parameters are present and considering all the parameters in the model respectively. Values of Seq SS and Adj SS are same stating that the design is orthogonal. Mean square (MS) shows the ratio of sum of squares by the degree of freedom. The ratio of mean square treatments and mean square error gives us the F-ratio, the F-ratio increases with the extent of effect of different factors.

\section{REGRESSION ANALYSIS}

Regression analysis is a statistical process for estimating the relationships among variables. It includes many techniques for modeling and analyzing several variables, when the focus is on the relationship between a dependent variable and one or more independent variables. In regression analysis, an equation is formed for the dependent variable in terms of all the influential parameters affecting the output. The following equation (1) is obtained from regression analysis using MINITABß:

Table 5. ANOVA Table

\begin{tabular}{|l|l|l|l|l|l|l|}
\hline SOURCE & DF & SEQ SS & ADJ SS & ADJ MS & F & P \\
\hline Main Effects & 6 & 11.5465 & 11.5465 & 1.92442 & 210.57 & 0.000 \\
\hline 2-Way Interactions & 11 & 2.0411 & 2.0411 & 0.18555 & 20.30 & 0.000 \\
\hline 3-Way Interactions & 4 & 0.7357 & 0.7357 & 0.18392 & 20.12 & 0.000 \\
\hline Residual Error & 106 & 0.9687 & 0.9687 & 0.00914 & & \\
\hline Lack of Fit & 42 & 0.6797 & 0.6797 & 0.01618 & 3.58 & 0.000 \\
\hline Pure Error & 64 & 0.2890 & 0.2890 & 0.00452 & & \\
\hline Total & 127 & 15.2920 & & & & \\
\hline
\end{tabular}

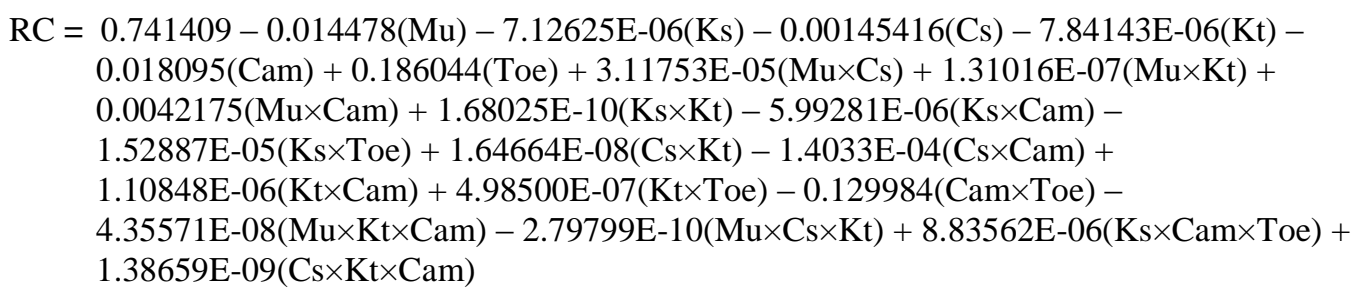

\section{SENSITIVITY ANALYSIS}

This experiment consists of many parameters which may affect the ride comfort either directly or indirectly. Sensitivity analysis helps in determining the behavior of response depending upon these parameters.Main effect plot in fig. 4 shows the impact of an individual parameter on the response, considering an average effect of all the other parameters. These parameters can be studied by observing their slope. A horizontal plot shows the incompetence of the parameter on the response whereas a vertical plot signifies that the parameter is highly sensitive. Fig shows an almost vertical plot for Cs and Kt signifying they are sensitive parameters for $\mathrm{RC}$ which is also verified by their P-value. Interaction plot in fig. 5 shows a plot consisting of 
two parameters which are dependent on each other. It shows combination of factors which have a particular effect on RC. Factors having insignificant main effect may have a significant interaction which effects the response (RC). In Fig the parallel lines in the plot shows absence of interaction effect whereas intersecting lines indicates interaction between the two factors.

\section{RESPONSE OPTIMIZATION}

Response Optimization is a function in Minitab ${ }^{\circledR}$ which calculates the optimum setting of the combination of all the included parameters as per the requirement of the user whether to minimize, maximize or achieve the target value for the response variable i.e. RC in our case. Minimization of RC was done using this tool and the value of all the influential parameters was obtained for the minimum value RC. This was then tested in the developed simulation model and compared with each other. Fig. shows the optimum values obtained for the different parameters. Table 6 shows the results for RC using the Response Optimization values, in the simulation model.

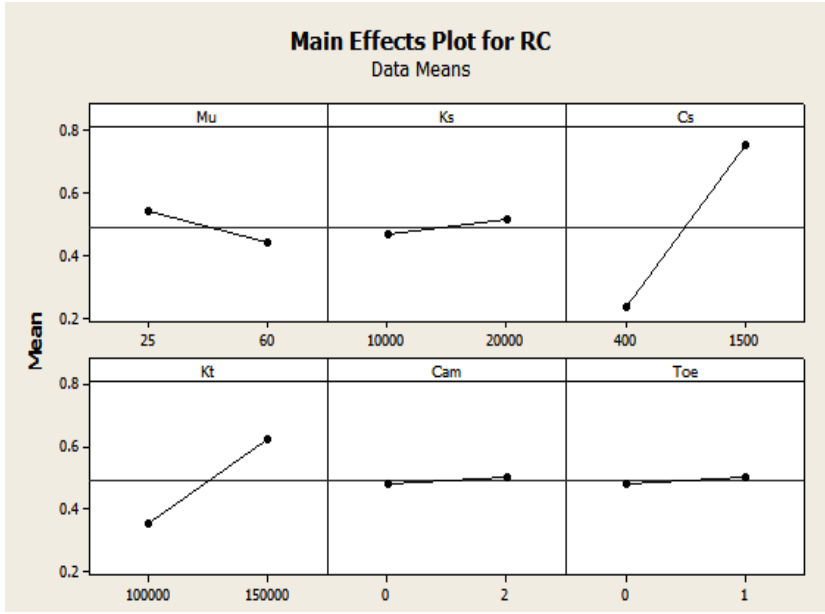

Fig.4 Main Effect Plot for RC

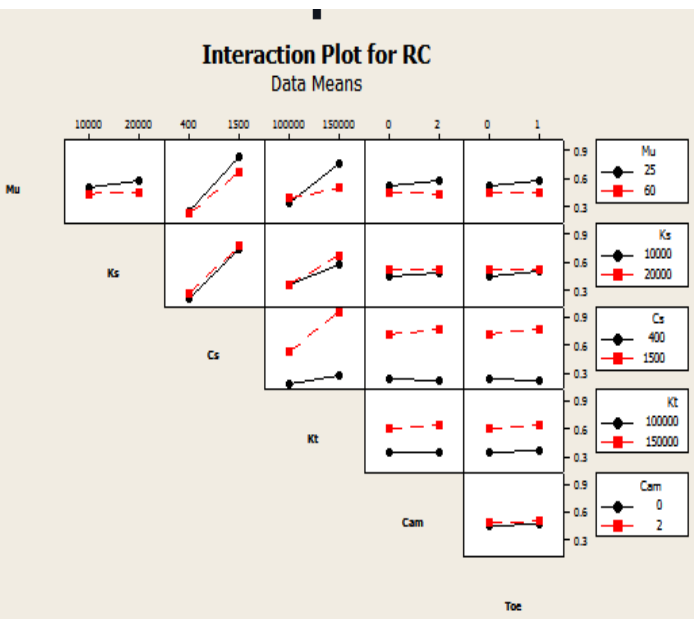

Fig.5 Interaction Plot for RC

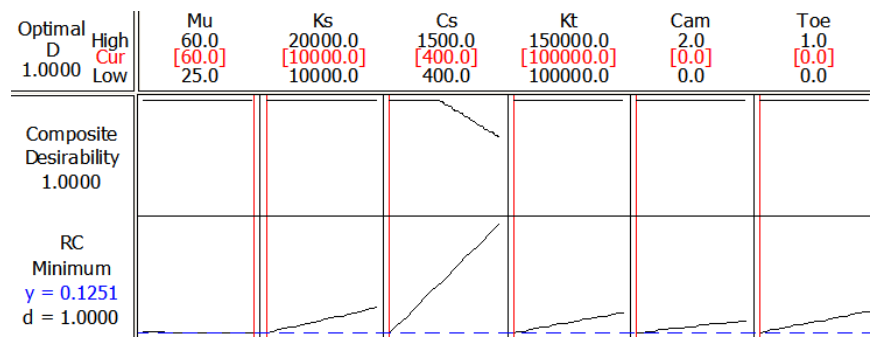

Fig. 6: Values of parameters obtained from Response Optimization.

Table 6: Verification of the RC value obtained in Response Optimization.

\begin{tabular}{|l|l|l|l|l|l|l|l|l|}
\hline $\begin{array}{l}\text { Un-Sprung } \\
\text { Mass(Mu) }\end{array}$ & $\begin{array}{l}\text { Spring } \\
\text { Stiffnes s(Ks) }\end{array}$ & $\begin{array}{l}\text { Damping } \\
\text { Coefficient(C.s) }\end{array}$ & Tire Stiffnes s(Kf) & $\begin{array}{l}\text { Cam } \\
\text { (deg) }\end{array}$ & $\begin{array}{l}\text { Toe } \\
\text { (deg) }\end{array}$ & $\begin{array}{l}\text { RC(Response } \\
\text { Optimizer) }\end{array}$ & $\begin{array}{l}\text { RC(Simulation } \\
\text { Model) }\end{array}$ & \begin{tabular}{l} 
Accuracy \\
\hline 60
\end{tabular} \\
\hline & 10000 & 400 & 100000 & 0 & 0 & 0.1251 & 0.1653 & $67.86 \%$ \\
\hline
\end{tabular}

\section{CONCLUSION}

In this study, RMS acceleration of sprung mass at a vehicle speed of $20 \mathrm{kmph}$ was obtained through ADAMS by altering various parameters like sprung and un-sprung mass, spring and damping coefficients, tire stiffness, camber and toe of quarter car simulations model. The minimum value of RC is obtained when $\mathrm{Ks}$, Cs, $\mathrm{Kt}$, Cam and Toe are set to low and $\mathrm{Mu}$ is set to high according to the specified range. The response optimization plot can also be used to obtain desirable RC values by altering the position of the vertical bar for various parameters. With the implementation of $2^{\mathrm{k}}$ Factorial Method, optimum values for the input parameters were obtained to obtain the best Ride Comfort value. The results obtained show that the difference between Rsq (93.67\%) and R-sq (adj) (92.41\%) is less. Such a model can be used not only to find the effect of individual parameters but also to find the effect of mutual interactions between them. 


\section{REFERENCES}

[1] A. C. Mitra, G. R. Kiranchand, S. B. Dhakare, M. S. Jawarkar, Optimization of Passive Suspension System for Enhancement of Ride Comfort, IOSR Journal of Mechanical \& Civil Engineering (IOSRJMCE),2016,1-8.

[2] Katu U.S., Desavale R.G. and Kanai R.A., Effect Of Vehicle Vibration On Human Body - RIT Experience, Rajarambapu Institute of Technology.

[3] Y. Zhang, Wei Chen, Liping Chen, Wenbin Shangguan, Non-stationary Random Vibration Analysis of Vehicle with Fractional Damping, 13th National Conference on Mechanisms and Machines (NaCoMM07), 2007.

[4] S. Mostaani, D. Singh, K.Firouzbakhsh,M.Taghi Ahmadian, Optimization of a passive vehicle suspension system for ride comfort enhancement with different speeds based on DOE method, Proc. of Int. Colloquiums on Computer Electronics Electrical Mechanical and Civil ,1(2),2011.

[5] A. Varghese, Influence of Tyre Inflation Pressure on Fuel Consumption, Vehicle Handling and Ride Quality, Chalmers University of Technology, Göteborg, Sweden 2013 Master's thesis 2013:75.

[6] A. Abdelghaffar, A. Hendy, O. Desouky, Y. Badr, S. Abdulla, R. Tafreshi, Effects of Different Tire Pressures on Vibrational Transmissibility in Cars, Proceedings of the 3rd International Conference on Mechanical Engineering and Mechatronics Prague, Paper No. 14, 2014,145.1-145.7.

[7] S. Prabhakar, K.Arunachalam, Simulation and Analysis of Passive Suspension system for Differrent Raod Profiles with Variable Damping and Stiffness Parameters, Journal of Chemical and Pharmaceutical Sciences,7,2015,32-36.

[8] M. Zehsaz, F. Vakili-Tahami, A. Fasihi, A. A. Majidi jirandi, Sensitivity of ride comfort to Suspension characteristics of an off-road vehicle under road excitation, International Journal of Emerging Technology and Advanced Engineering, Volume 2, Issue 5, May 2012.

[9] J. Marzbanrad, Masoud Mohammadi and Saeed Mostaan, Optimization of a Passive Vehicle Suspension System for Ride Comfort Enhancement with Different Speeds Based on Design of Experiment Method (DOE) , Journal of Mechanical Engineering Research, Vol. 5(3), pp. 50-59, March 2013.

[10] A.C. Mitra, Kiranchand G. R., Tanushri Soni, Nilotpal Banerjee, Design of Experiments For Optimization Of Automotive Suspension System Using Quarter Car Test Rig, 12th International Conference on Vibration Problems, ICOVP 2015, Procedia Engineering 144 ( 2016 ) 1102 - 1109.

[11] A. C. Mitra, Ameya Pande, Soham Kanthale, Nikhilesh Gulhane, Akash Sharma, Nilotpal Benerjee, Optimization of Vehicle Suspension Parameters by Design of Experimentation using a Quarter Car Test rig, International Conference on Theoretical, Applied, Computational and Experimental Mechanics, ICTACEM-2014/136, Proceedings of ICTACEM 2014, 2014.

[12] A. C. Mitra, Faizanuddin Siddique, Sagar Agarwal, Hrushikesh Kaduskar, Sanket Atreb, Nilotpal Benerjee, Multi-Objective Optimization of Vehicle Suspension System using Genetic Algorithm, International Conference on Theoretical, Applied, Computational and Experimental Mechanics, ICTACEM-2014/105, Proceedings of ICTACEM, 2014.

[13] A. C. Mitra, Gourav. J. Desai, Saaish. R. Patwardhan, Parag H. Shirke, Waseem M. H. Kurne, Nilotpal Banerjee, Optimization Of Passive Vehicle Suspension System By Genetic Algorithm, 12th International Conference on Vibration Problems, ICOVP 2015, Procedia Engineering 144,2016,1158 - 1166.

[14] J. Liu, Yongjun Shen, Shaopu Yang, Parameter Optimization of Passive Vehicle suspension based on Invariant Points Theory, International Journal on smart sensing and intelligent systems, 6(5),2013.

[15] A. Mehmood, Ahmad Ali Khan, Ayaz Mehmood, Optimization of Suspension Damping using Different Mathematical Car Models, International Journal of Mechanical Engineering, ISSN : 2277-7059, 3(10), 2013.

[16] A. Elsawaf and T. Vampola, Passive Suspension System Optimization Using PSO to Enhance Ride Comfort when Crossing Different Types of Speed Control Profiles, Journal of Traffic and Logistics Engineering,Vol. 3(2) 2015.

[17] Z. Chi, Yuping He and Greg F. Naterer, Design Optimization of Vehicle Suspensions with a Quarter Vehicle Maodel, Received ,University of Ontario Institute of Technology, Oshawa, Ontario, 2007.

[18] A.Shirahatti, P.S.S. Prasad, Pravin Panzade, M.M. Kulkarni, Journal of the Brazilian Society of Mechanical Sciences and Engineering, J. Braz. Soc. Mech. Sci. \& Eng, Vol.30 (1),2008.

[19] R Alkhatib, G Nakhaie Jazar, M.F Golnaraghi, Optimal design of passive linear suspension using genetic algorithm, Journal of Sound and Vibration, 275(3-5) 2004.

[20] Shijil P, A. Vargheese, Aswin Devasia, Christin Joseph, Josin Jacob, Design and Analysis of suspension system for an All Terrain Vehicle, International Journal of Scientific \& Engineering Research,7(3)3,2016.

[21] M. Mahmoodi-Kaleibar, I. Javanshir, K. Asadi, A. Afkar, A. Paykani, Optimization of suspension system of off-road vehicle for vehicle performance improvement,J. Cent. South Univ.(2013)20: 902-910.

[22] P.Senthil kumar. R.Kalidas, K.Sivakumar, E.Hariharan, B.Gautham, R.Ethiraj, Application of Taguchi method for optimizing passenger-friendly vehicle suspension system, International Journal of Latest Trends in Engineering and Technology (IJLTET), 2 (1), 2013.

[23] A. C. Mitra, Mukul Jawarkar, Tanushri Soni, Kiranchand G. R., Implementation of Taguchi Method for Robust Suspension Design, 12th International Conference on Vibration Problems, ICOVP 2015, Procedia Engineering 144, 2016,77 - 84.

[24] A. Florea,Ioana Ileana Cofaru, Lucian ROMAN, Nicolae Cofaru, Applying the Multi-objective Optimization Techniques in the Design of Suspension System, Journal of Digital Information Management,14 (6),2016.

[25] G.Ali Hassaan, Car Dynamics using Quarter Model and Passive Suspension, Part VI: Sprung-Mass Step Response, IOSR Journal of Computer Engineering (IOSR-JCE), 17(2), 2015.

[26] G.Ali Hassaan : Car Dynamics using Quarter Model and Passive Suspension, Part III : A Novel Polynomial Hump, IOSR Journal of Mechanical and Civil Engineering (IOSR-JMCE), 12(1), 2015. 